SANTOS, B.R.L. - Programa de assistência de enfermagem a cliente portadores de danos cardiovasculares, no ambulatório de um hospital geral e de ensino de Porto Aiegre, RS, Rev. Bras. Enf.: RS, 36: 274-281, 1983.

10. LOPES, Hélio. Assistência hospitalar e saúde pública. Revista Paulista de Hospitais, São Paulo, 11 (10): 40, out. 1963.

11. MUXFELDT, Léa C. F. Assistência de Enfermagem ao cliente. Anais. Congresso Brasileiro de Enfermagem, Camboriú, 17-27, 1977.

12--Configuração para o planejamento do Serviço de Enfermagem em Saúde Pública no Hospital de Clínicas de Porto Alegre. São Paulo, USP, Faculdade de Saúde Pública, 1978. Tese Mestr.

13.-Assistência de Enfermagem ao cliente em clínica de atendimento externo. Revista do Hospital de Clínicas de Porto Alegre e Faculdade de Medicina da Universidade Federal do Rio Grande do Sul, Porto Alegre, 1 (2): 107-110, dez. 1981.

14. WIRSIG, Claus A. O papel do hospital-escola na prestação de serviços de saúde à comunidade. Vida Hospitalar, São Paulo, 8 (1): 3-6, 1974.

\title{
A ENFERMEIRA NO DIAGNÓSTICO DO ESTADO DE SAÚDE NUTRICIONAL DE PRÉ-ESCOLARES E ESCOLARES UTILIZANDO MEDIDAS SIMPLIFICADAS
}

\author{
* Vera Heloisa Pileggi Vinha \\ ** Wildce da Graça Araújo \\ ** Jussara Aparecida de Angelis \\ ** Ana Lúcia de Mattia \\ ** Janice Olívia Galvane \\ ** Rosa Maria de Mattos \\ ** Wilma Toyoko Oyadomari \\ ** Sônia Maria Alves de Paiva \\ ** Valéria Whady Rebehy
}

$\mathrm{ReBEn} / 08$

VINHA, V.H.P. e colaboradoras - A enfermeira no diagnóstico do estado de Saúde nutricional de pré-escolares e escolares utilizando medidas simplificadas. Rev. Bras. Enf.: RS, 36: 281-296, 1983.

\begin{abstract}
A desnutrição constitui a principal causa de mortalidade e morbidade no país. Aqueles que não morrem no $1 .^{\circ}$ ano de vida sobrevivem num estado de subnutrição e desnutrição entrando desta forma na idade pré-escolar e escolar. Considerando que a população de pré-escolares e escolares dentro de duas décadas será a mão de obra economicamente produtiva do pais, a enfermeira, junto a esta população, deve fazer primeiramente o diagnóstico do seu estado de saúde nutricional usando medidas simplificadas, não onerosas; $e$, posteriormente, atuar segundo as prioridades estabelecidas.
\end{abstract}

\section{RESUMO}

A desnutrição constitui a 1. causa de morte na infância, quer como causa básica ou associada. Deve ser vista também em termos de sobreviventes e danos que advém à saúde. É grande o contigente populacional de pré-escolares e escolares que sobrevivem num estado crônico de subnutrição ou desnutrição. Ações de saúde tomadas visando estas crianças devem ser precedidas de um exame simplificado, realizado pela enfermeira, permitindo um diagnóstico de toda a população. Neste estado a en-

* Professor Assistente Doutor da Escola de Enfermagem de Ribeirão Preto.

** Alunos do 4. ${ }^{\circ}$ ano - habilitação em Enfermagem de Saúde Pública em 1981, que participaram e colaboraram com a pesquisa. 
VINHA, V.H.P. e colaboradoras - A enferrneira no diagnóstico do estado de Saúde nutricional de pré-escolares e escolares utilizando medidas simplificadas. Rev. Bras. Enf.: RS, 36: 281-296, 1983.

fermeira baseou-se para o diagnóstico das crianças nos valores de peso, estatura e aplicação da fita de Shakir. A população constitui-se de 86 escolares de uma escola situada em zona peri-urbana da cidade de Ribeirão Preto. Diagnosticou-se subnutrição em $80,71 \%$ da população. As ações de enfermagem visando estas crianças foram a de incentivo à direção da escola e aos órgãos governamentais a fim de que a população em pauta tivesse elevado o padrão de alimentação. Paralelamente efetuou-se tratamento para pediculose, aplicação de vacinas, pequenos curativos e encaminhamento de 5 crianças a Instituições de Saúde para prosseguirem tratamento anteriormente abandonados.

\section{INTRODUÇÃO}

A desnutrição constitui a primeira causa de morte na infância, quer como causa básica ou associada. Para os menores de 5 anos a associação entre a desnutrição e sarampo e desnutrição e gastroenterites, em termos de mortalidade foi da ordem de $70 \%$ (Coordenação de Proteção Materno Infantil, 1975).

Não se deve falar em desnutrição apenas enfocando mortalidade, porém em termos de sobreviventes e danos para a saúde. Assim para o pré-escolar, que constitui o grupo mais vulnerável à desnutrição, os coeficientes de mortalidade são maiores. Mesmo assim, se compararmos os dados do Brasil com os de outros países da América observa-se que morre grande número de pré-escolar; ou-seja o número de óbitos é bem maior que o esperado (Vinha e Dutra de Oliveira, 1981).

O pré-escolar constitui um grupo vulnerável do ponto de vista nutricional, porque se encontra numa fase intensa de crescimento e desenvolvimento. Acresça-se, que ele não goza de uma posição de destaque na estrutura social da família, isto não só no aspecto alimentar como também psicológico.

A sociedade não oferece creches, parques infantis e escolas para atender à demanda de préescolares, o que permitiria uma melhor alimentação. Daí contarmos com elevadas taxas de morbidade e mortalidade nesta faixa populacional (Gandra, 1973).

Destaca-se ainda que o pré-escolar sobrevive em um estado crônico de subnutrição e é desta forma que ele entra para a escola quando completa 7 anos. Quanto mais grave e mais precoce for o processo de desnutrição que ele sofreu, durante sua infância, menor será o seu Quociente Intelectual, daí termos crianças com sérias dificuldades de aprendizado e pouco rendimento escolar. Portanto, isto significa, no futuro uma mão de obra barata, constituída em sua maioria de sub-empregados (Bengoa, 1974; Cravioto, 1966; Kevany, 1966; OMS, 1974).

Se medidas sérias não forem tomadas durante a fase escolar pouco poderá ser feito no futuro. Nesta fase é grande o contingente populacional reunido, o que facilita qualquer processo educativo; é nesta fase que ele é altamente receptivo às orientações dadas na escola pelo professor, é ainda bastante fácil um trabalho com as famílias, tendo como caso piloto o pré-escolar ou escolar. (Acresça-se que, durante o período em que ele freqüenta a escola, poderá ser-lhe oferecido um suplemento alimentar que corresponda a $30 \%$ de suas necessidades (Toledo, 1973).

A enfermeira desde a sua formação deve estar inserida na realidade nacional. Deve ter uma formação generalista. Fazer diagnósticos de pessoas ou de populações ou ainda de situações, utilizando métodos, técnicas ou medidas adequadas ao ambiente em que atua, e aos recursos humanos e materiais disponíveis. Deve ainda ter por base o diagnóstico do estado de saúde da população infantil do Brasil.

Conhecedora da realidade nacional e dos riscos prováveis que a criança tem de morrer e adoecer, deve a enfermeira procurar diagnosticar as causas que põem em risco a vida da criança.

Portanto o objetivo deste trabalho é relatar uma experiência de assistência de enfermagem a uma população escolar infantil e como realizamos o diagnóstico do estado de saúde nutricional, através de medidas simplificadas.

\section{MATERIAL E MÉTODO}

A população constitui-se de 86 pré-escolares e escolares de uma escola da zona peri-urbana na cidade de Ribeirão Preto. As crianças são moradoras não só na zona periférica, como em chácaras que circunvizinham a cidade.

A escola funciona das 8 às 11 horas de $2^{\text {a }}$ às $6^{\text {a }}$ feiras. Foram feitas 2 visitas por semana por 8 alunas do curso de graduação, habilitação em enfermagem de Saúde Pública. Num, primeiro encontro foi feito reunião com a direção da escola e professores, visando prestar esclarecimentos quanto ao nosso objetivo e obter informações necessárias, quanto aos recursos humanos e materiais disponíveis, a fim de adequar nossos objetivos a realidade da instituição e das crianças. A seguir foi feita reunião com os pais para informá-los do trabalho que seria realizado junto de seus filhos e perguntar se a criança 
VINHA, V.H.P. e colaboradoras - A enfermeira no diagnóstico do estado de Saúde nutricional de pré-escolares e escolares utilizando medidas simplificadas. Rev. Bras. Enf.: RS, 36: 281-296, 1983.

apresentava alguma doença e/ ou se tomava algum medicamento e imunização anteriormente recebida. Posteriormente, cada dupla de alunos ficou responsável por uma classe para realização dos exames de saúde. Constaram em se obter informações da própria criança se tinha algum problema, verificação do peso e estatura, inspeção da pele e mucosas e circunferência braquial (critério adotado por Shakir 1980).

Utilizou-se uma fita composta de 3 cores: vermelho, amarelo e verde. A mensuração foi feita da seguinte forma: até 5 anos de idade, mediu-se com referida fita a circunferência braquial e para os maiores de 5 anos a aferição foi feita no punho - Shakir - 1980 .

Quanto as cores, vermelho significa desnutrição, amarelo subnutrição e verde nutrido.

De posse do diagnóstico do estado de saúde de todos os escolares, novo diálogo foi mantido com os professores e foi solicitado a presença dos pais.

Posteriormente as ações de enfermagem foram adequadas ao diagnóstico da situação de saúde da população de escolares e constituiu de: melhoria da merenda escolar, imunização e cuidados de enfermagem à pediculose e pequenos curativos de ferimentos e escoriações e, educação da merendeira quanto ao preparo e apresentação de alimentos e das crianças quanto a aceitação e valorização da merenda escolar.

A duração do trabalho foi de 10 semanas, isto indo a escola 2 vezes por semana no período das 8 às 11 horas. Perfazendo um total de 20 visitas.

\section{RESULTADOS}

A Escola de $1^{\circ}$ grau, objeto do presente estudo pertence a uma instituição filantrópica que é responsável pela educação das 86 crianças.

Fornece material escolar, parte das roupas e calçados, alimentação e transporte. Apenas os professores e o dentista são pagos pela prefeitura. As crianças permanecem na escola durante quatro horas. Recebem o desjejum (leite em média $200 \mathrm{ml}$ ) e uma refeição (sopa $\pm 300 \mathrm{ml}$ ) às 10 horas.

A prefeitura fornece $50 \%$ do suplemento alimentar que é recebido pelo CNAE (Companhia Nacional de Alimentação Escolar - Setor Municipal de Alimentação Escolar). As demais quantidades são obtidas através de Campanha da Fraternidade, que funciona aos domingos, pelo quadro de sócios donativos, campanhas particulares e promoções.

A população que freqüenta esta escola é constituída de 86 pré-escolares e escolares do grupo etário $3 \vdash 15$ anos.

A tabela 1 mostra que o maior percentual de freqüência $33,6 \%$ encontra-se na $1{ }^{\text {a }}$ série, seguido da 2 a série com $24,1 \%$ e pré-escola $22,1 \%$. Os menores percentuais de freqüência encontram-se nas 3 . e 4 a séries com $12,6 \%$ e $7,0 \%$ respectivamente.

Quanto aos grupos etários, a maior concentração de freqüência está no grupo etário $10 \vdash 11$ anos com $13,9 \%$, seguido dos grupos etários $7 \vdash 8,8 \vdash 9,9 \vdash 10,11 \vdash 12$ anos com percentual de $12 \%$. Os menores valores encontram-se nos grupos' etários $13 \vdash 14,14 \vdash 15$ e $3 \vdash 4,4 \vdash 5$ com $2,3 \%$ e $1,2 \%$ respectivamente.

Quanto ao sexo, a distribuição está relativamente igual para ambos com $42,0 \%$ para o masculino e $44,0 \%$ para o feminino.

A distribuição da população por grupo etário desta tabela estão projetados no gráfico I.

A tabela 2 mostra a distribuição das crianças segundo o peso, grupo etário e sexo. Observase que crianças de grupos etários diferentes apresentam os mesmos intervalos de peso. As maiores freqüências, 24 e 20 foram para o intervalo de peso $20 \vdash 30 \mathrm{~kg}$ tanto para o sexo masculino como feminino, respectivamente.

O gráfico II mostra a análise comparativa de pesos, seguindo os padrões de normalidade* (Marcondes, e col., 1975) para a nossa população e mostra que para o sexo feminino os valores são inferiores, excetuando-se aqueles de 11 anos, onde os valores se igualam. Para o sexo masculino os valores estão bem abaixo do esperado.

As maiores diferenças para menos foram para as idades de 4 a 6 anos (pré-escolar). Para aqueles de 8,9 e 10 anos não houve aumento, de peso, ascendendo novamente a partir dos 11 anos, sendo que aos 12 anos ele se encontra com os valores médios normais.

A tabela 3 mostra os valores obtidos quanto a estatura, relacionando-a com grupo etário e sexo.

* A terminologia esperada ou padrão ou valor dentro do limite de normalidade ou de tolerância tem o mesmo significado. 
VINHA, V.H.P. e colaboradoras - A enfermeira no diagnóstico do estado de Saúde nutricional de pré-escolares e escolares utilizando medidas simplificadas. Rev. Bras. Enf.: RS, 36: 281-296, 1983.

O gráfico III mostra que para o sexo masculino os valores médios de estatura encontrados, apresentam-se de um modo geral, inferior a média padrão; excetuando-se para as idades de 5,7 e 9 anos, cujos valores encontram-se acima da média padrão. Para o sexo feminino os valores médios de estatura encontrados foram inferiores aos valores padrão. Para aqueles de 8 anos os valores médios de estatura se encontram: e para aqueles de 4 e 5 anos os valores médios de estatura se encontram acima do valor padrão.

O gráfico IV mostra que os valores concentram-se abaixo da média de peso esperada para o sexo feminino. Quanto a altura, ainda para o sexo feminino, os valores também concentram-se em torno da média padrão, sendo que a maior concentração encontra-se abaixo da média padrão e alguns abaixo dos limites inferiores de normalidade.

$\mathrm{O}$ gráfico $\mathrm{V}$ mostra que para o sexo masculino, os valores médios de peso concentram-se, predominantemente, abaixo do valor médio padrão. Quanto a altura, ainda para o sexo masculino, os valores médios de estatura encontram-se em torno da média padrão, com maior concentração inferior a média padrão.

A tabela 4 mostra os alunos que freqüentam o grupo escolar segundo grupo etário, sexo e estado nutricional critério adotado por (SHAKIR, 1980).

Das 83 crianças que foram submetidas a fita de Shakir para avaliar estado nutricional, verificou-se que $46,98 \%$ apresentou subnutrição (cor amarela); $36,76 \%$ apresentou desnutrição (cor vermelha e $19,24 \%$ apresentou-se nutrido (cor verde).

Quanto ao sexo, não houve praticamente diferença para aqueles que se enquadram na cor amarela, para o feminino foi $22,89 \%$ e para o masculino $24,09 \%$.

Tanto para os que se encontram na cor vermelha como verde, a diferença entre os dois sexos foi da ordem de $4,8 \%$; sendo que para cor verde houve um ligeiro predomínio para o masculino, e para a cor vermelha o foi para o feminino.

Quanto aos grupos etários para a cor verde-nutrido - o grupo etário que apresentou o maior percentual foi de $12 \vdash 13$ anos com $71,42 \%$, seguido do grupo etário $10 \vdash 11$ anos com $27,27 \%$. Em terceiro lugar, encontram-se os grupos etários $5 \vdash 6$ anos e $6 \vdash 7$ anos com $14,28 \%$ e $12,50 \%$ respectivamente. Finalmente, encontram-se os grupos etários $9 \vdash 10$ anos $\in 11 \vdash 12$ anos com $9,09 \%$.

Quanto a cor amarela - subnutrição - os maiores percentuais encontram-se nos grupos etários $9 \vdash 10$ anos e $11 \vdash 12$ anos com $72,72 \%$. Seguido dos grupos etários $7 \vdash 8$ anos e $8 \vdash 9$ anos com $63,63 \%$. Para o grupo etário $10 \vdash 11$ anos foi $54,00 \%$.

Quanto a cor vermelha - desnutrição - os maiores percentuais o foram para os grupos etários $6 \vdash 7$ anos e $5 \vdash 6$, anos com $75,00 \%$ e $71,42 \%$ respectivamente. Obteve-se $36,36 \%$ para os grupos etários $7 \vdash 8$ e $8 \vdash 9$ anos. Os menores valores foram para os grupos procedentes com $18,8 \%$.

Estes valores estão projetados no gráfico VI.

\section{DISCUSSÃO}

A utilização de métodos simplificados para diagnóstico da situação de saúde nutricional de uma criança ou de um grupo populacional é de suma importância, pois o diagnóstico pode ser feito pela enfermeira que, de posse dos resultados estabelece um programa de ação embasado em escala prioritária. Por outro lado em locais onde não há possibilidade de atuação da enfermeira ela poderá ensinar aos professores esses métodos ou técnicas que uma vez simples, será facilmente utilizado. Posteriormente junto com eles estabelece um programa de ação.

A população de pré-escolares e escolares perfazendo um total de 86 , constituiu uma amostra da população brasileira, que reside em zonas peri-urbanas das cidades.

É importante que se ressalte, que a massa de pré-escolares e escolares reside nas zonas periurbanas das cidades; e tem uma renda familiar mensal percapita no máximo $30 \%$ do salário mínimo (Vinha e Dutra de Oliveira, 1981). Infere-se que os alunos que freqüentam escola tenham uma renda familiar mensal igual ou inferior a mencionada, pois não só residem em zona peri-urbana, como em chácaras vizinhas, como empregados. Acresça-se, o aspecto como as crianças comparecem à escoia, vestuário inadequado às estações do ano e em más condições de conservação e higiene. Além disso, grande número de crianças referem que não tomam o desjejum antes de irem à escola.

$\mathrm{O}$ fato de encontrarmos crianças em idade avançada na $1^{\mathrm{a}}$. série e séries subseqüentes, pode se atribuir a uma dificuldade de aprendizado, fato este confirmado pelos professores. Infere-se, que estas crianças vem sofrendo carência alimentar, desde as idades mais precoces, crescendo em estado de subnutrição ou desnutrição, sofrendo os danos da desnutrição que interferem na maturação do Sistema Nervoso Central, sendo em alguns casos irreversíveis (Kevany, 1966). 
VINHA, V.H.P. e colaboradoras - A enfermeira no diagnćstico do estado de Saúde nutricional de pré-escolares e escolares utilizando medidas simplificadas. Rev. Bras. Enf.: RS, 36: 281-296, 1983.

Observa-se crianças na $1^{\text {a }}$ série até 13 anos e na $2^{\text {a }}$ série até 15 anos. Na 3 a série o número de crianças é de apenas 11 e na 4 . série apenas 6 . Este descréscimo pode ser atribuído a uma dificuldade de aprendizado, a medida que os assuntos tornam-se mais complexos, motivo pelo qual ocorre o abandono. Isto aliado às necessidades que têm as famílias de aumentar a renda familiar, leva o escolar a trabalhar e faz com que a desistência ocorra de forma mais precoce.

$\mathrm{O}$ peso e a estatura inferiores aos limites de tolerância que foram estabelecidas em camadas de nossa população consideradas sadias e normais, deve-se a uma carência alimentar que persiste até o presente momento. Sabe-se que quase $100 \%$ das crianças fazem o desjejum na escola ingerindo apenas leite $(+200 \mathrm{ml})$ em quantidade que nem sempre satisfaz; ingerem a sopa $(+300 \mathrm{ml})$ que é oferecida às 10 horas e ao retornarem para as suas casas pouco ou nada recebem de alimentos, informação esta que é confirmada não só pelas crianças, como também pelos professores que as conhecem com maior profundidade, bem como pelos seus familiares. Portanto, o suplemento alimentar que é oferecido embora esteja dentro do pré-estabelecido, $30 \%$ das necessidades da criança (Toledo, 1973) não supre as necessidades totais da criança nesta faixa etária, o que não é responsabilidade da escola.

Estas afirmativas são confirmadas quando se faz a aferição da circunferência braquial, onde verificou-se que apenas $19,24 \%$ das crianças apresentaram-se nutridas, $46,9 \%$ subnutridas e $33,73 \%$ desnutridas. Se somarmos os percentuais de subnutridos e desnutridos obteremos um total de $80,71 \%$ de crianças carentes do ponto de vista nutricional. E aferição de peso e estatura com valores abaixo do normal. Portanto, o diagnóstico da situação de saúde dessa população de escolares é a subnutrição e desnutrição.

A dificuldade de aprendizado, o pouco rendimento escolar são conseqüências da falta de alimento desde idades precoces até idade atual. Acresça-se que criança com fome não se interessa pelos estudos.

A enfermeira deve atuar de forma a melhorar o estado nutricional destas crianças interferindo junto à direção da escola, junto aos órgãos públicos, CNAE, LBA e outros e ainda junto às famílias visando melhorar o padrão de alimentação da criança. Conseguiu-se ainda que a sopa fosse distribuída no período de férias.

Após a solução desses problemas prioritários outras medidas serão tomadas, levando em conta as prioridades do grupo, portanto eliminando-se em etapas as causas que põem em risco esta população infantil.

Não foi feito programa educativo visando conscientizar as crianças quanto ao valor dos alimentos, porque isto só deverá ser feito após um diagnóstico completo da situação econômica e de recursos alimentares de que as famílias dos escolares dispõem. O escolar não é elemento ativo para modificar os hábitos alimentares de sua família. A educação seria unilateral, o que não alteraria os hábitos familiares e deixaria o escolar em conflito. Por outro lado não é questão apenas de hábito, mas de elevação das condições econômicas da família.

Ensinou-se a criança a valorizar e a aceitar a merenda escolar. A merendeira foi treinada quanto ao preparo e apresentação adequada do alimento, procurando avaliar diariamente a aceitação das crianças e quando necessário modificando a dieta quando não aceita pelas mesmas.

Com relação aos pais, numa etapa posterior, eles farão parte de um processo educativo, pois somente eles serão capazes de alterar para melhor o padrão alimentar em nível domiciliário. À medida que forem surgindo resultados nesse sentido, as crianças serão educadas visando a aceitação de novos alimentos que serão introduzidos na sua alimentação.

Para um trabalho rotineiro de higiene escolar após a aferição dos pesos e estaturas, os valores obtidos devem ser lançados no gráfico (Marcondes, 1971) que informa eficientemente quem se enquadra nos limites de normalidade. Em pouco tempo tem-se o diagnóstico da população infantil quanto ao seu peso e estatura.

Sabe-se que as crianças têm outras necessidades, entretanto, deve ser solucionado em caráter prioritário os problemas da subnutrição e da desnutrição. Posteriormente devem ser tomadas outras medidas que visem a criança como um ser bio-psico-social, mas isto deve estar adequado à escala prioritária.

\section{CONCLUSÕES}

1. O peso, a estatura e a verificação da circunferência braquial para diagnóstico da situação de saúde nutricional de crianças pré-escolares e escolares são eficientes pois:

1.1 São medidas simplificadas, não onerosas, quer do ponto de vista económico como de pessoal. 
VINHA, V.H.P. e colaboradoras - A enfermeira no diagnóstico do estado de Saúde nutricional de préescolares e escolares utilizando medidas simplificadas. Rev. Bras. Enf.: RS, 36: 281-296, 1983.

1.2. Sãomedidas facilmente realizadas pela enfermeira e pessoal auxiliar, podendo ainda ser ensinada a professores em instituições mais carentes.

1.3. São medidas precisas e que formam um diagnóstico certo.

2. O diagnóstico da situação de saúde da população de pré-escolares e escolares foi subnutrição e desnutrição atingindo a $80,71 \%$ das crianças.

3. Os percentuais de crianças nutridas, subnutridas e desnutridas foram da ordem de $19,24 \% ; 46,98 \% ; 33,73 \%$ respectivamente. médio padrão.

4. A maior concentração de valores médios de peso e estatura encontram-se abaixo do valor

5. A média de peso e estatura das crianças foram inferior ao padrão.

6. O decréscimo do número de alunos da 1 . para $2^{\mathrm{a}}$ série foi $31,03 \%$, da $2^{\mathrm{a}}$ para a $3{ }^{\mathrm{a}}$ série foi $52,38 \%$ e da 3 . $^{\text {a }}$ para a 4 . série foi $54,54 \%$.

7. A presença de crianças além da idade esperada para a 1 a série é $65,52 \%$, para a $2^{\text {a }}$ série é $80,96 \%$, para a $3^{\mathrm{a}}$ série é $96,91 \%$ e para a $4^{\text {a }}$ série é $66,67 \%$.

\section{SUMMARY}

Malnutrition is the most important factor in children's death, as basic or associated cause. Mistake that is not good for health, there are great number of people in preschool and schoolar age who survived in chronic state of undernutrition and badnutrition.

The nurse as a member of the health team would perform a fundamental role in the precocious diagnosis of under nutrition and malnutrition, using simple technics as weight, higher Shakir strip.

The population sample is constituted of eighth six children that studied in a peripherical school of Ribeirão Preto, SP.

In $80,17 \%$ of the children we have found undernutrition and malnutrition. The nurse's action having in view the schoolars and pre-schoolar children have been an incentive to the school manegement and to the government institutes aiming to get better the nutritional state and alimentary patterns of this studied population. Parallel carry out treatment for pediculose, vaccinate, small curatives and children's guiding to Health's institution to continue treatment left premiousey.

\section{BIBLIOGRAFIA}

1. BENGOA, J.M. - El problema de la malnutrición. Cron OMS 28 (1): 307, 1974.

2. CRAVIOTO, J. - La desnutrición proteicocalórica. Bol of Sanit Panam 61 (4): 285-304, 1966 :

3. GANDRA, X. R. - Assistência alimentaria por medio de centros de educación y alimentación del preescolar. Bol Of Sanit Panam 74 (4): 302-314, 1973.

4. KEVANY, J.P. - Problemas de nutrición del niño preescolar en América Latina. Bol Of Sanit Panam 60 (4): 282-292, 1966.

5. MARCONDES, \& col. - Estudo Antropométrico de Crianças Brasileiras de zero a doze anos de idade. Anais Nestlé, n. $84,1971$.

6. ORGANIZAÇÃO MUNDIAL DA SAÚDE - Malnutrición y desarrollo mental. Cron OMS 28 (3): 10-110, 1974.

7. PUFFER, R.R.Y.; C.V. SERRANO. Características de la mortalidad en la niñez. Informe de la Investigación Interamericana de Mortalidad en la ninēz. Organização Pan-Americana da SaúdePublicação Científica 262. Washington, D.C., 1973. 510 págs.

8. SHAKIR - International Year of the Child c/o Institute of Child Health, London, 1980.

9. TOLEDO, S.A.: - O problema da nutrição Escolar no Estado de São Paulo - Secretaria da Educação, Serviço de Saúde Escolar - Conferência pronunciada na Câmara Municipal de São Paulo, 12 de dezembro de 1973, mimeografada.

10. VINHA, V.H.P.; DUTRA DE OLIVEIRA, J. E. - Programa Comunitário de Alimentação; Bol Of Sanit Panam 90 (3), 1981. 
VINHA, V.H.P. e colaboradoras - A enfermeira no diagnóstico do estado de Saúde nutricional de pré-escolares e escolares utilizando medidas simplificadas. Rev. Bras. Enf.: RS, 36: 281-296, 1983.

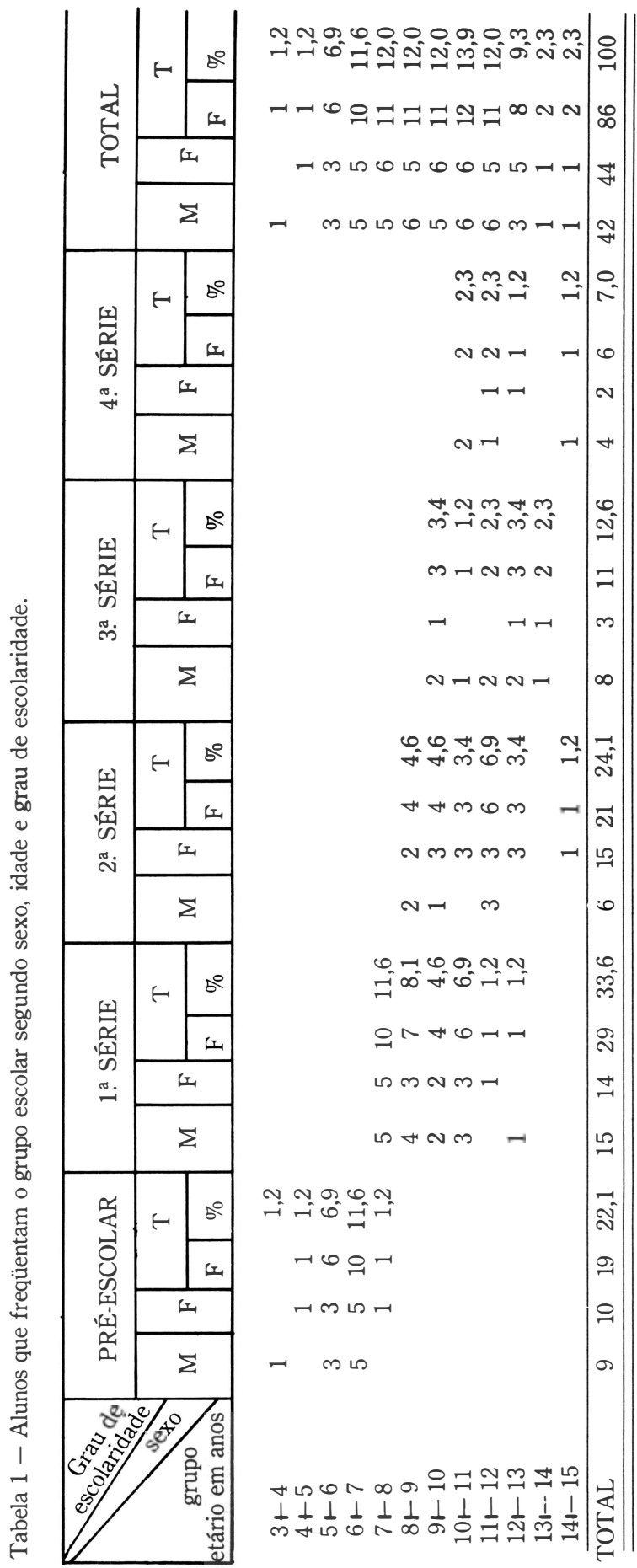


VINHA, V.H.P. e colaboradoras - A enfermeira no diagnóstico do estado de Saúde nutricional de pré-escolares e escolares utilizando medidas simplificadas. Rev. Bras. Enf.: RS, 36: 281-296, 1983.

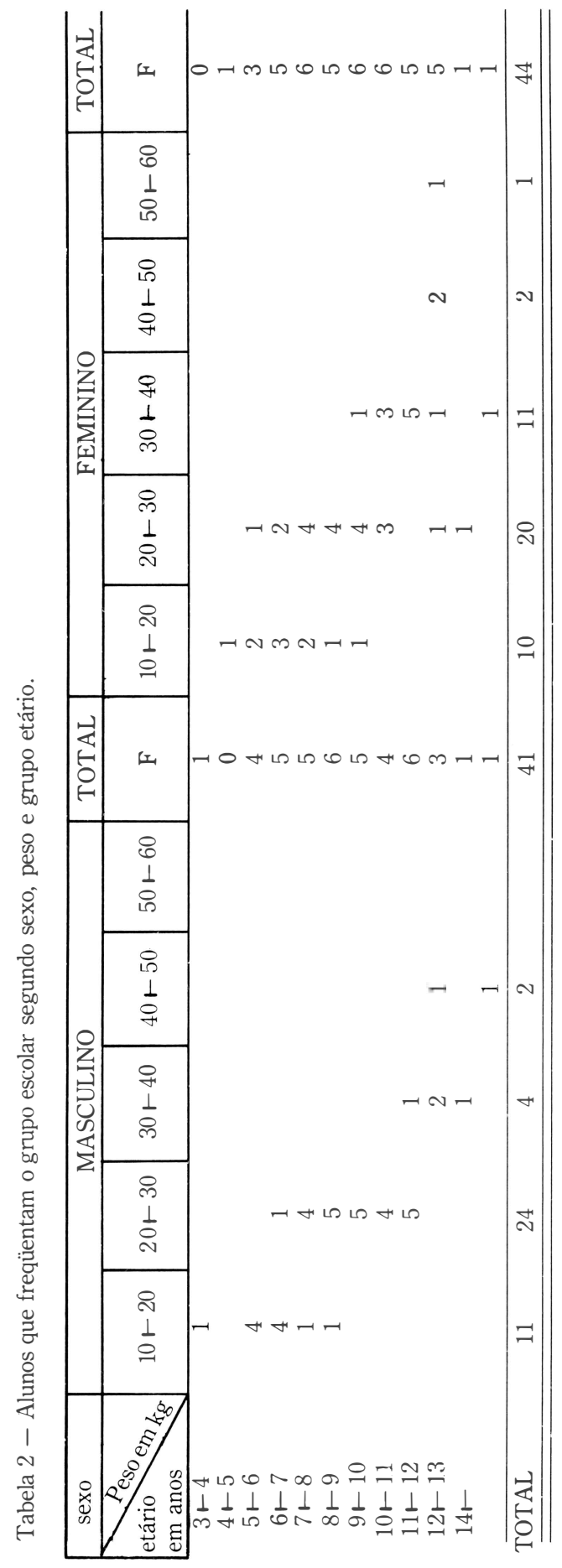


VINHA, V.H.P. e colaboradoras - A enfermeira no diagnóstico do estado de Saúde nutricional de pré-escolares e escolares utilizando medidas simplificadas. Rev. Bras. Enf.: RS, 36: 281-296, 1983.

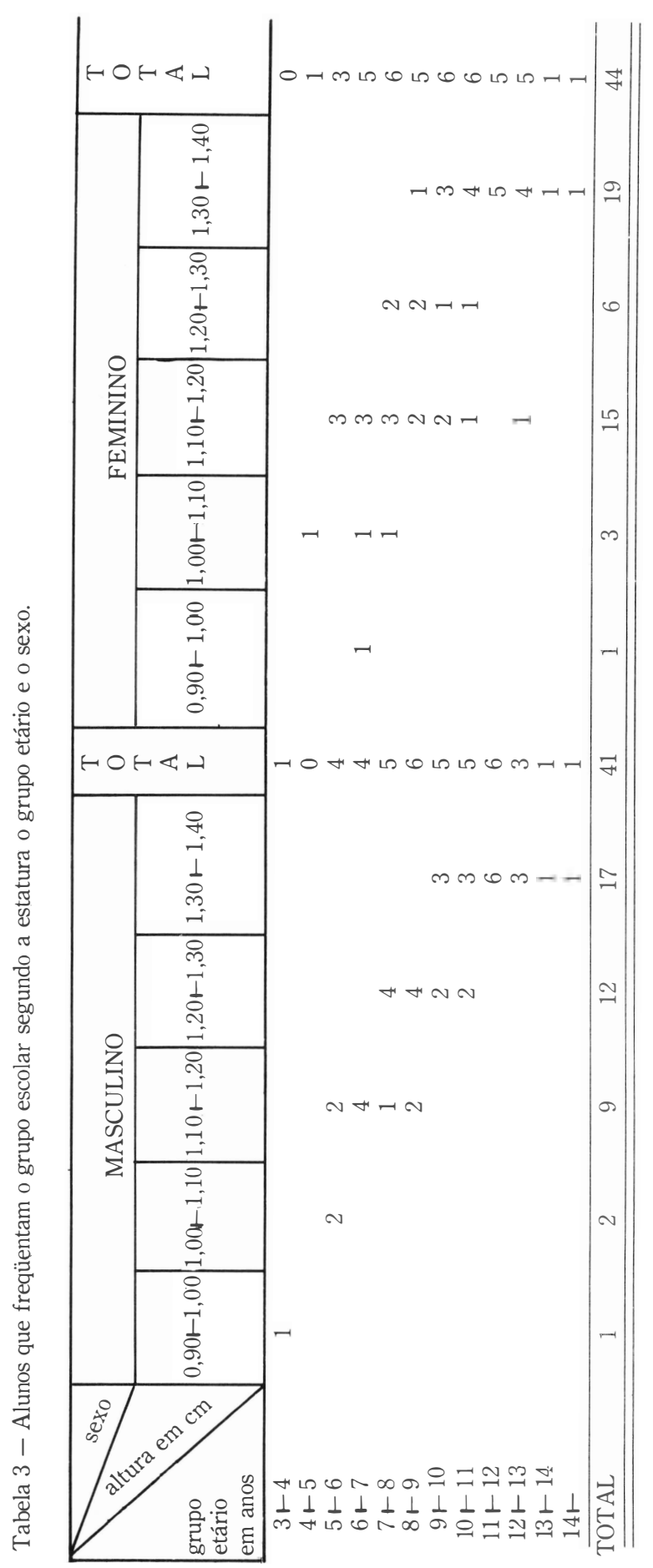


VINHA, V.H.P. e colaboradoras - A enfermeira no diagnóstico do estado de Saúde nutricional de préescolares e escolares utilizando medidas simplificadas. Rev. Bras. Enf.: RS, 36: 281-296, 1983.

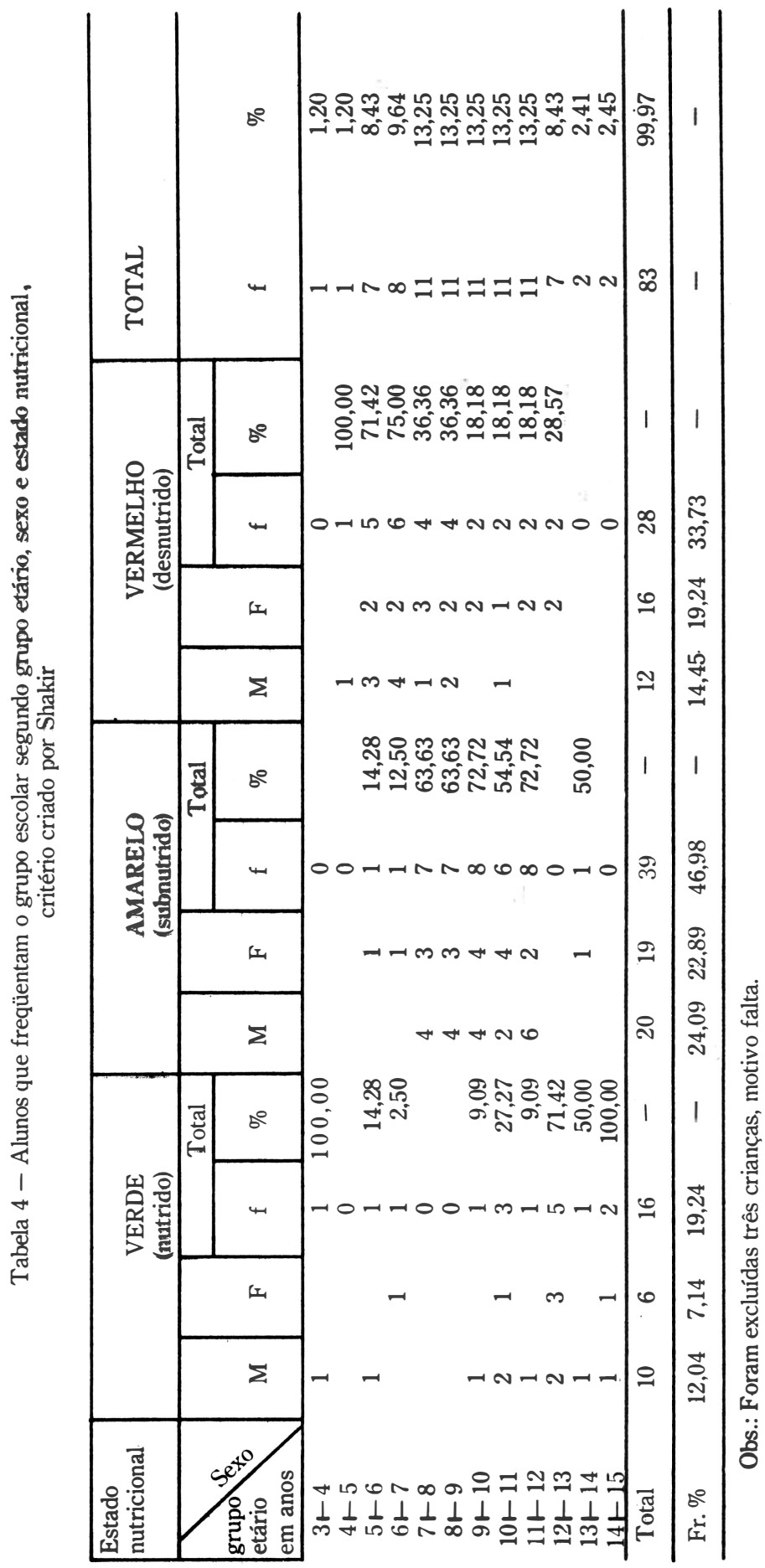


VINHA, V.H.P. e colaboradoras - A enfermeira no diagnóstico do estado de Saúde nutricional de pré-escolares e escolares utilizando medidas simplificadas. Rev. Bras. Enf.: RS, 36: 281-296, 1983.

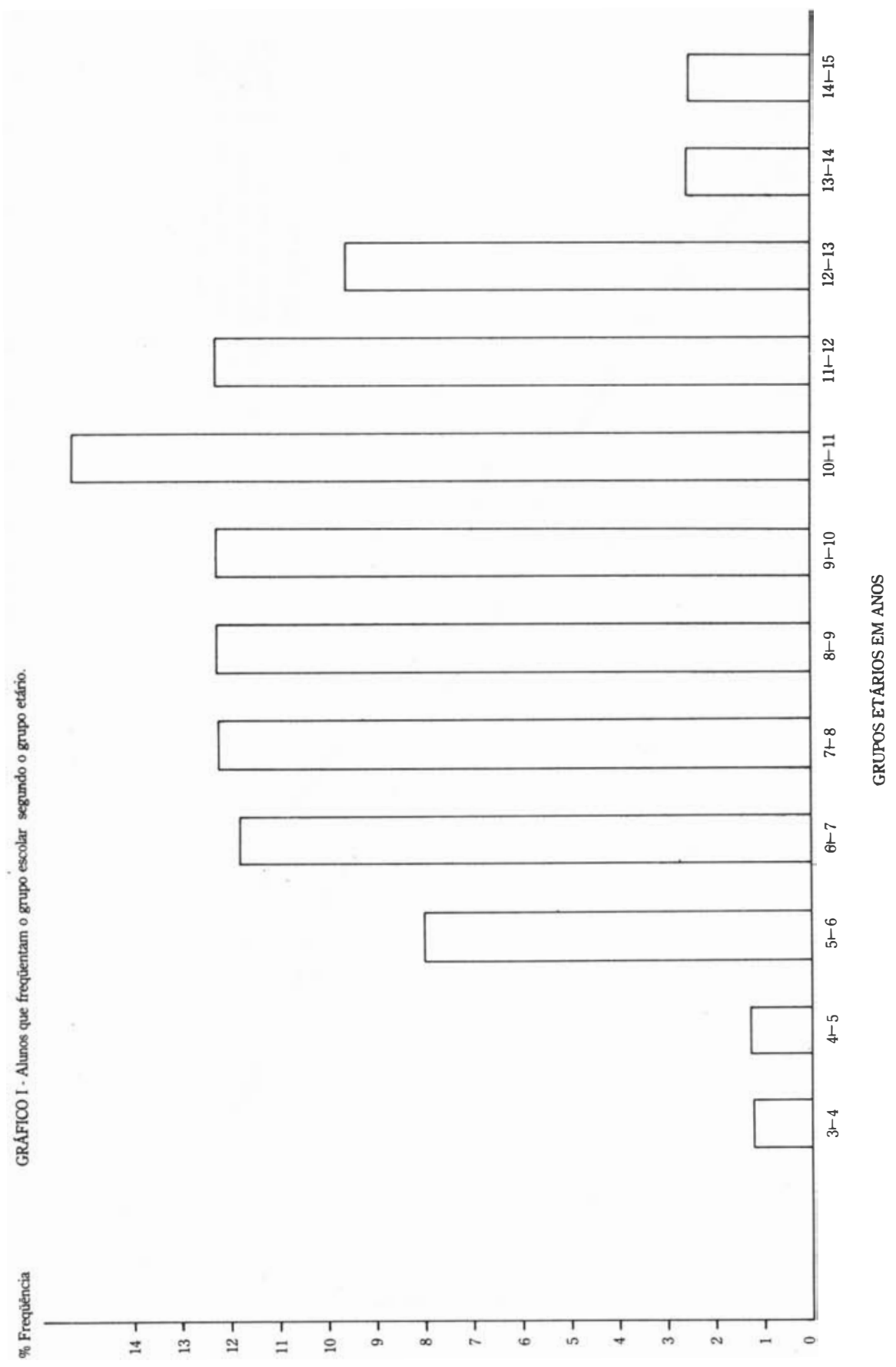


VINHA, V.H.P. e colaboradoras - A enfermeira no diagnóstico do estado de Saúde nutricional de pré-escolares e escolares utilizando medidas simplificadas. Rev. Bras. Enf.: RS, 36: 281-296, 1983.

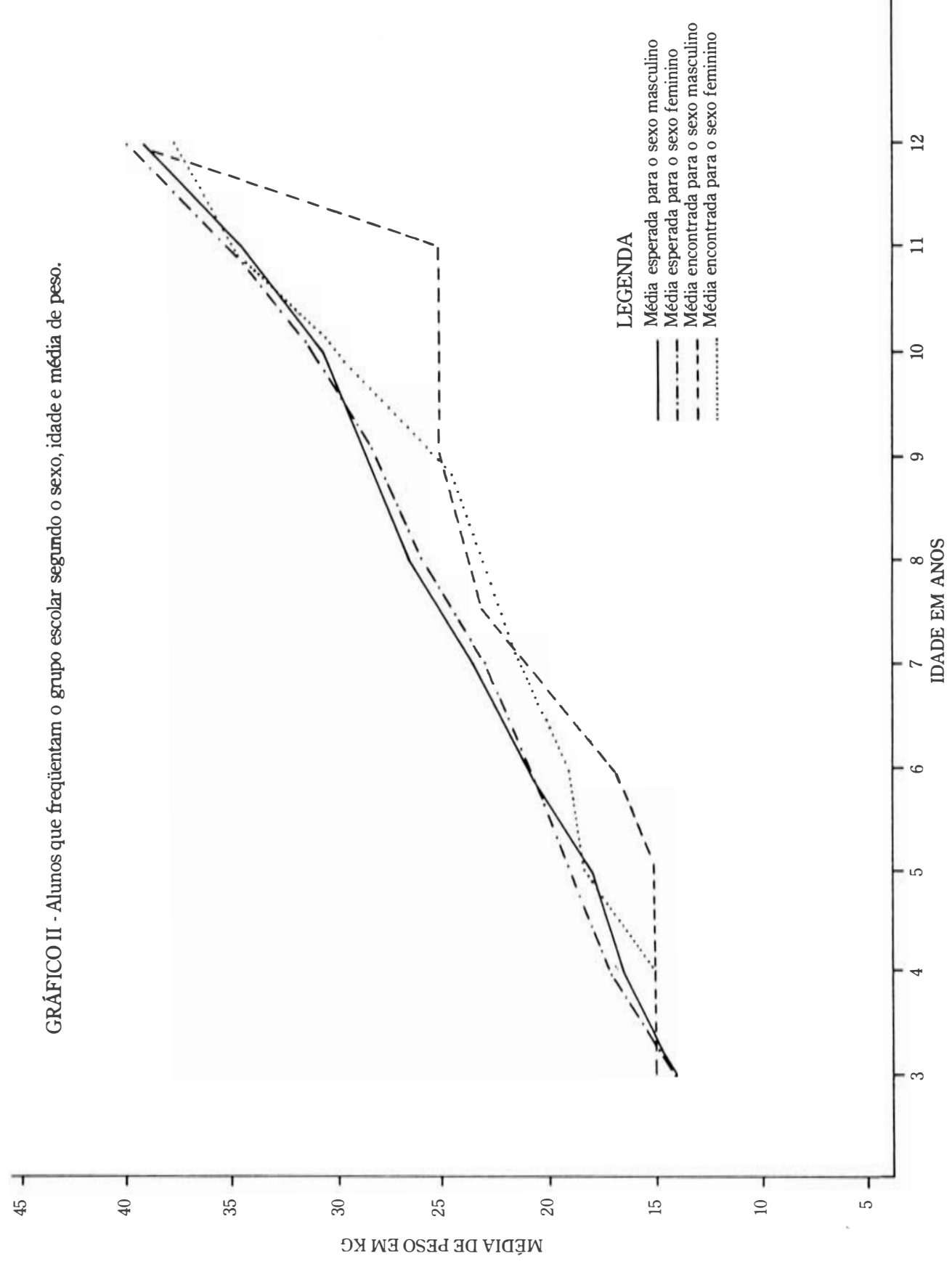


VINHA, V.H.P. e colaboradoras - A enfermeira no diagnóstico do estado de Saúde nutricional de pré-escolares e escolares utilizando medidas simplificadas. Rev. Bras. Enf.: RS, 36: 281-296, 1983.

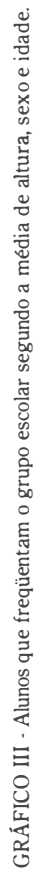

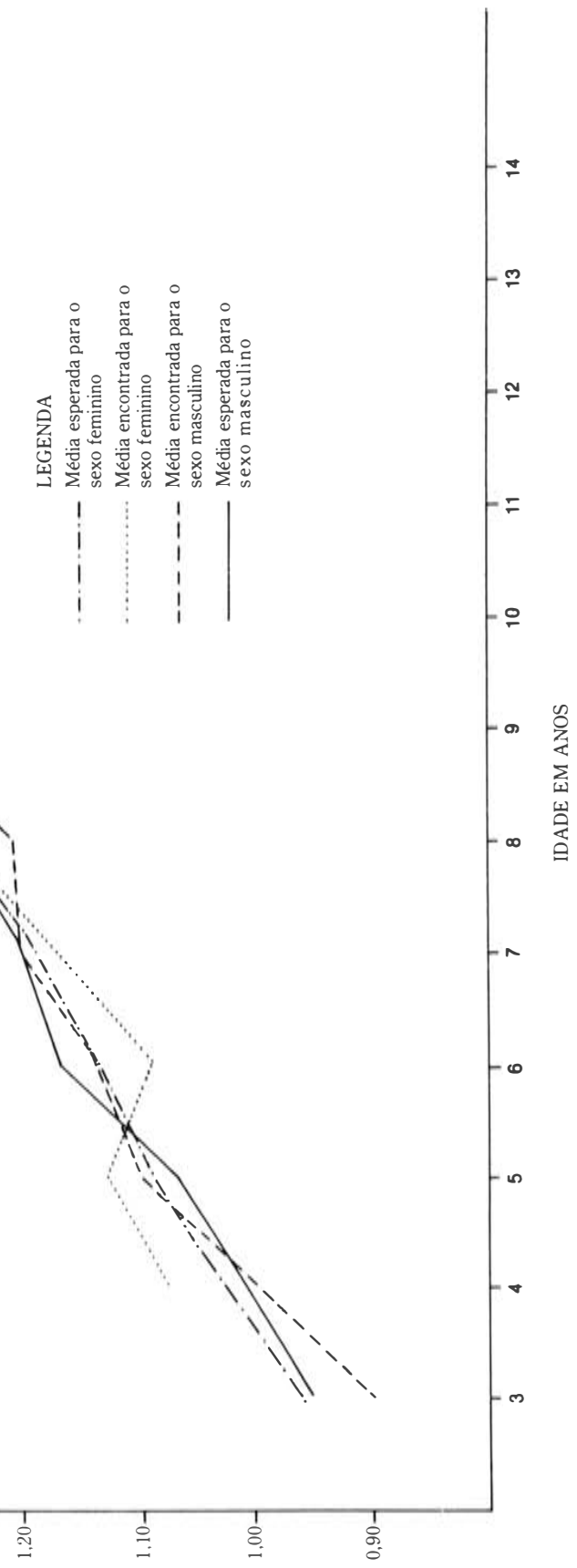

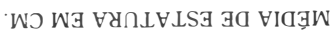


VINHA, V.H.P. e colaboradoras - A enfermeira no diagnóstico do estado de Saúde nutricional de pré-escolares e escolares utilizando medidas simplificadas. Rev. Bras. Enf.: RS, 36: 281-296, 1983.

GRÁFICO IV - Alunos do sexo feminino que freqüentam o grupo escolar segundo, peso, estatura e idade - comparação com valores padrão.

PESO E ALTURA DE MENINAS - 3 a 12 ANOS

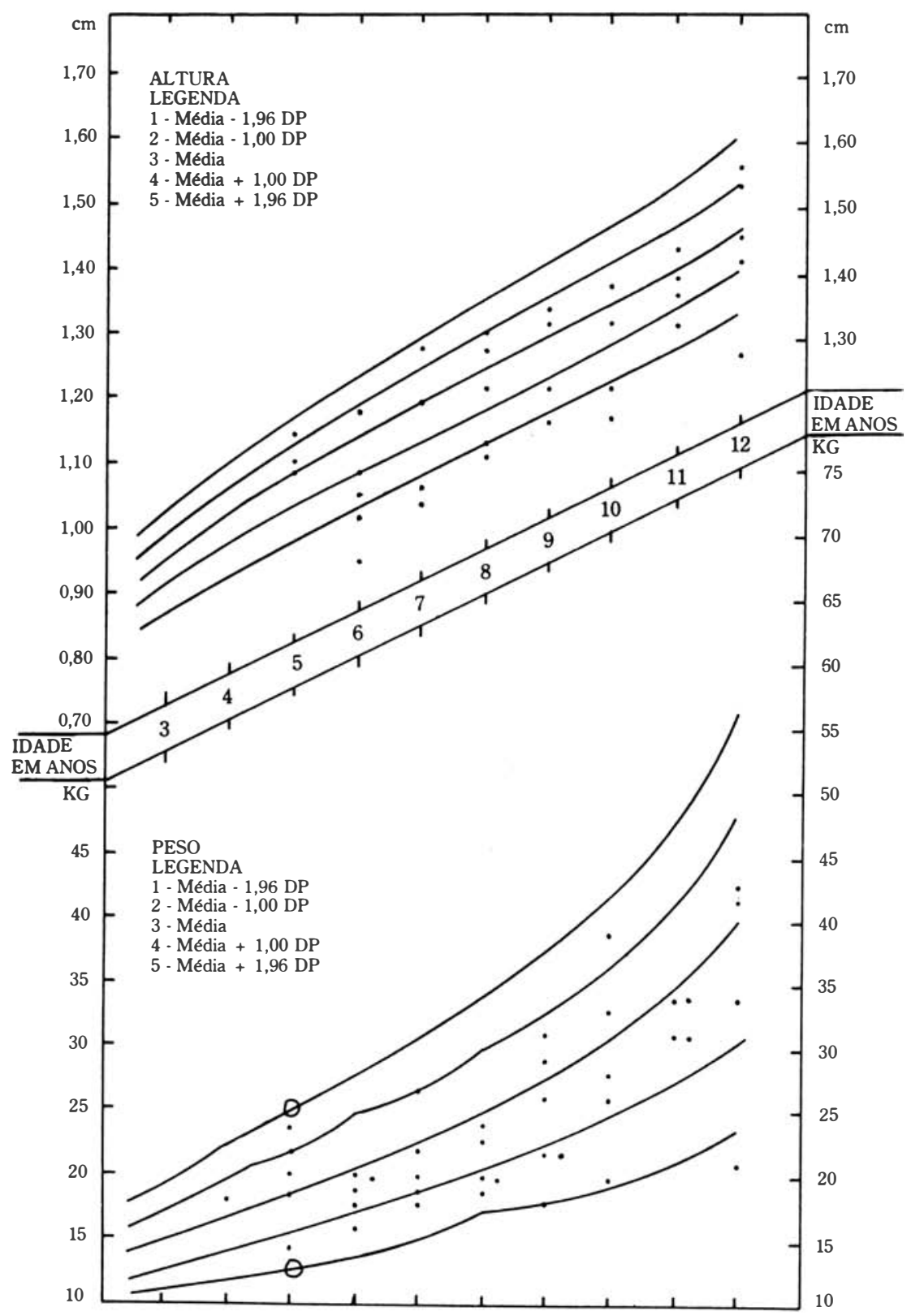


VINHA, V.H.P. e colaboradoras - A enfermeira no diagnóstico do estado de Saúde nutricional de pré-escolares e escolares utilizando medidas simplificadas. Rev. Bras. Enf.: RS, 36: 281-296, 1983.

GRÁFICO V - Alunos do sexo masculino que freqüentam o grupo escolar segun do, Peso, estatura e idade - comparaçào com valores padrảo.

PESO E ALTURA DE MENINOS - 3 a 12 ANOS

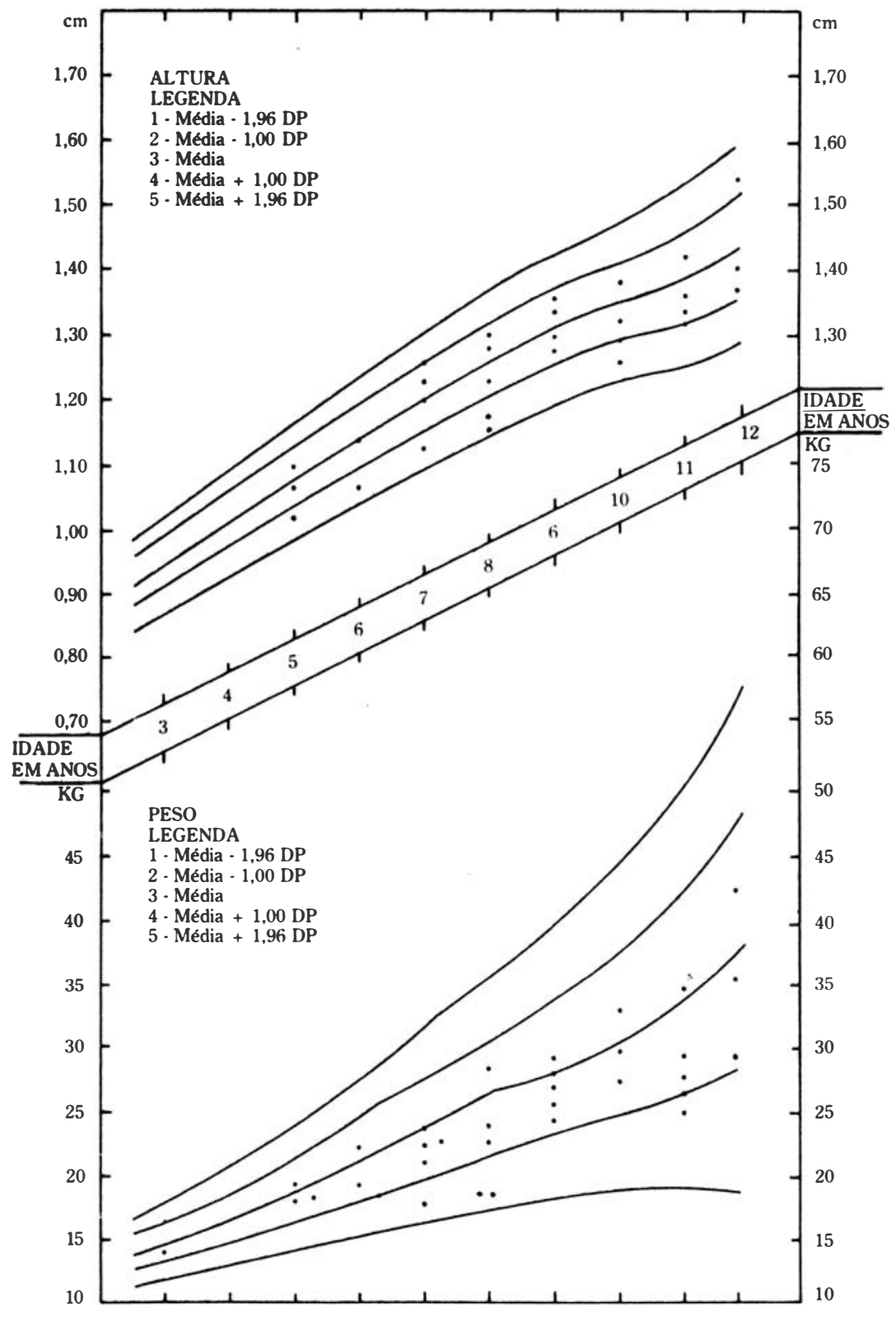


VINHA, V.H.P. e colaboradoras - A enfermeira no diagnóstico do estado de Saúde nutricional de pré-escolares e escolares utilizando medidas simplificadas. Rev. Bras. Enf.: RS, 36: 281-296, 1983.

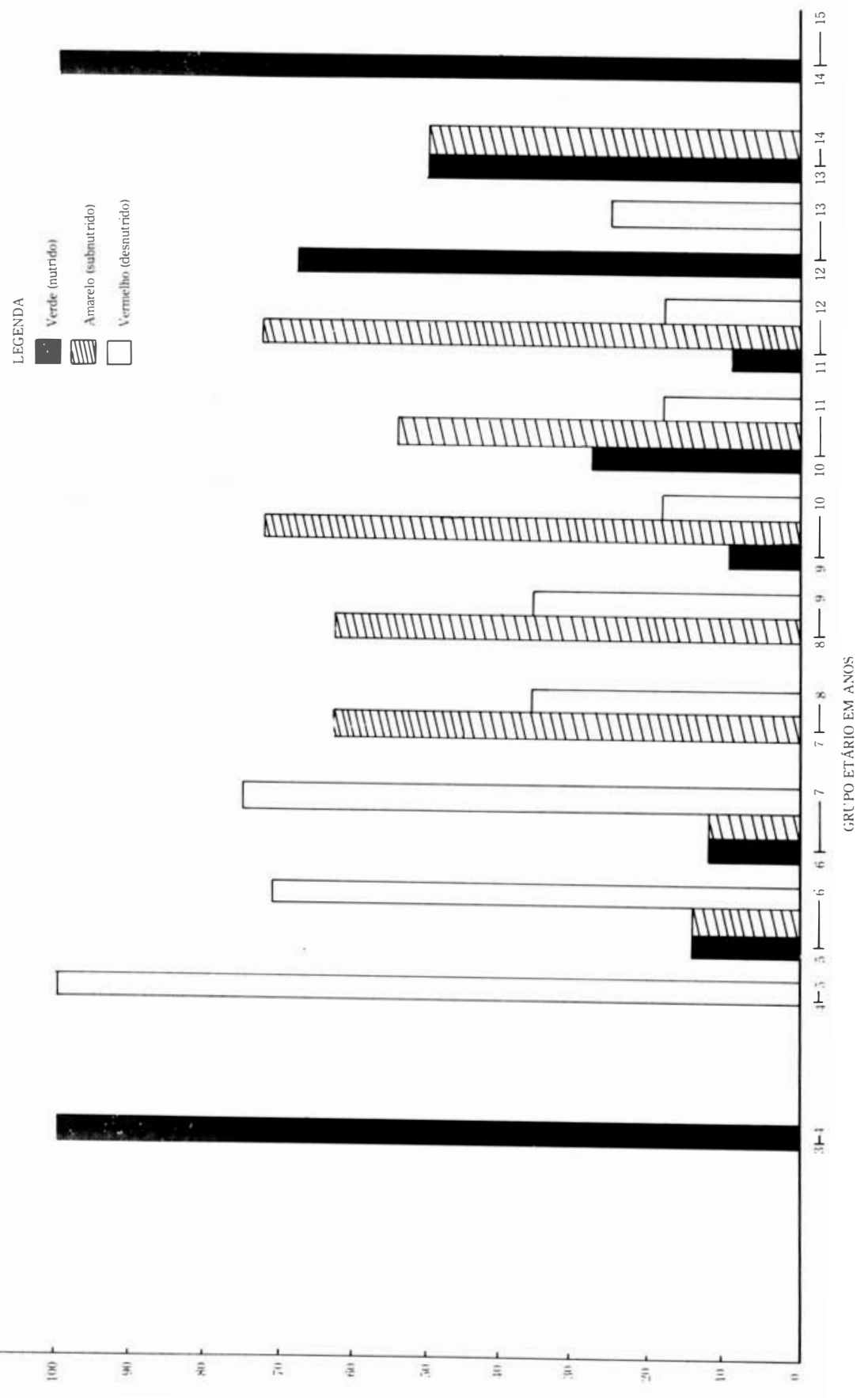

